\title{
Knit Line Failure of a Glass-Filled Polysulfone Pipe Fitting and Fractographic Comparison to Laboratory-Produced Fractures
}

\author{
Ronald J. Parrington, P.E., FASM ${ }^{1}$ \\ 1. Engineering Systems Inc. (ESI), Aurora, IL, USA
}

A 20\% glass-fiber-reinforced polysulfone (PSU) pipe fitting cracked after approximately six months in service. Failure analysis revealed that the fitting cracked along a knit line, a potentially weak planar interface. The failure mechanism is most likely brittle stress rupture (i.e., slow crack growth). Stress rupture failures occur after time under constant loading. However, since cracking occurred along the knit line, a monotonic (one time loading) failure would appear similar and cannot be ruled out. The loads that caused the failure can be a combination of applied loads (e.g., internal pressure, installation, unexpected impacts) and residual or frozen-in stresses. Cracking initiated at a location where the knit line coincides with a notch-like design feature (i.e., a pipe stop) on the fitting that acts as a stress raiser and exacerbates the stress level. Testing revealed that the tensile strength in the hoop direction of a new fitting was reduced by approximately $20 \%$ at the knit line. The cause of the fitting failure is a knit line of inferior strength and/or higher than expected stresses. Potential preventive actions include: (1) redesign the mold or die cavity to relocate the knit lines away from stress raisers (e.g., pipe stops); (2) optimize molding parameters (time, temperature and pressure) to strengthen the cohesive bond at the knit line; and (3) reduce unnecessary loads/stresses on the fitting such as undesirable loads from installation and residual stresses from molding.

The failure investigation included visual examination, scanning electron microscopy (SEM), materialography, Fourier transform infrared (FTIR) analysis, thermogravimetric analysis (TGA), melt flow index, and tensile testing of the failed fitting and a new fitting.

A subtle knit or weld line is visible adjacent to the parting line. A knit line or weld line is created during molding when material flow splits to flow around features such as holes in the part design and then reconverges on the other side of the feature. By the time the two material fronts reconverge, the molten plastic may have already started to skin over and, therefore, the cohesive bonding at a knit line is never as strong as the surrounding material. Furthermore, in the case of glass fiber reinforced plastics, the glass fiber orientation tends to be parallel to the knit line. This creates a plane of weakness as the parallel glass fibers do not strengthen the part in the direction transverse to the knit line. The crack path observed on the failed fitting is similar to the knit line location on the new fitting. The fracture surfaces display smooth, flat areas and rough areas. The smooth, flat areas are consistent with cracking along a knit line. As a rule of thumb, heavily filled and reinforced plastics, such as the failed $20 \%$ glass-fiberreinforced PSU fitting, do not display many (if any) meaningful fracture surface features on both the macro- and microscale. However, the flat surface texture and radial lines suggest that the fracture originated at a corner or shoulder of the fitting, which acts as a stress raiser. Furthermore, the crack path and knit line run along a pipe stop, which also acts as a stress raiser.

The fracture surfaces of the failed fitting were examined with an SEM. Smooth, flat areas of the fracture surface were compared to rough areas. On the microscale, the rough areas of the failed fitting fracture surface display much more material stretching than the smooth/flat regions. In the smooth/flat regions of the failed fitting, the glass fibers run parallel to the fracture surface and there is much less glass fiber 
pullout compared to the rough areas. In addition, the fracture surfaces of laboratory-produced fast bend, slow tensile, and slow tensile knit line fractures were examined. The three laboratory-produced fractures display much less material stretching than seen in the rough areas of the failed fitting, but slightly more than seen in the smooth/flat regions of the failed fitting. The rapid bend fracture exhibits more stretching than the two slow tensile fractures. The amount of glass fiber pullout for the rapid bend fracture is high and comparable to the rough areas of the failed fitting. Some fiber pullout is observed in the slow tensile fracture (non-knit line). Very little fiber pullout is observed for the knit line fracture.

Transverse and longitudinal cross sections were prepared through the knit line on the new fitting for microscopic examination. The knit line was not revealed by glass fiber orientation in either sample. However, the knit line appears to be visible as a shallow $(\sim 0.2 \mathrm{~mm})$ depression on the fitting outer diameter (OD). Tensile tests were performed per ASTM D2290 on two ring tensile specimens machined from the new fitting to compare the fracture surfaces with the failed fitting and to quantify the knit line strength. The knit line specimen failed at a $20 \%$ lower load.

FTIR (ASTM E1252) and TGA (ASTM E1131) analyses confirmed that both fittings are 20\% glassfilled PSU. Melt flow index testing was performed on both fittings per ASTM D1238. Melt flow testing revealed that there is not a molecular weight degradation issue.

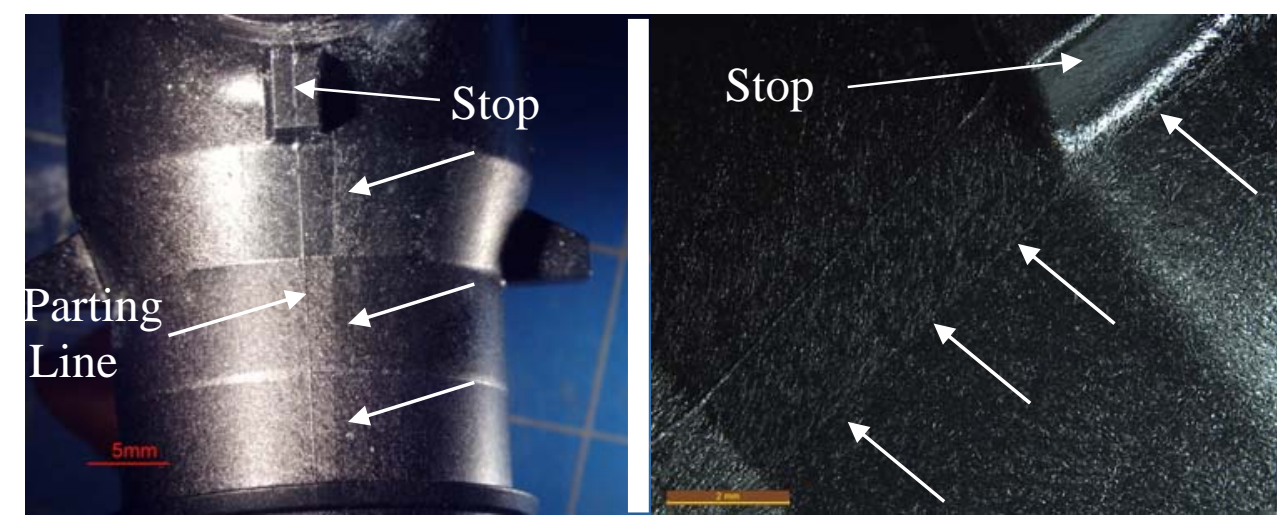

Figure 1. Images of the knit line, which runs roughly parallel to the parting line and along the pipe stop.

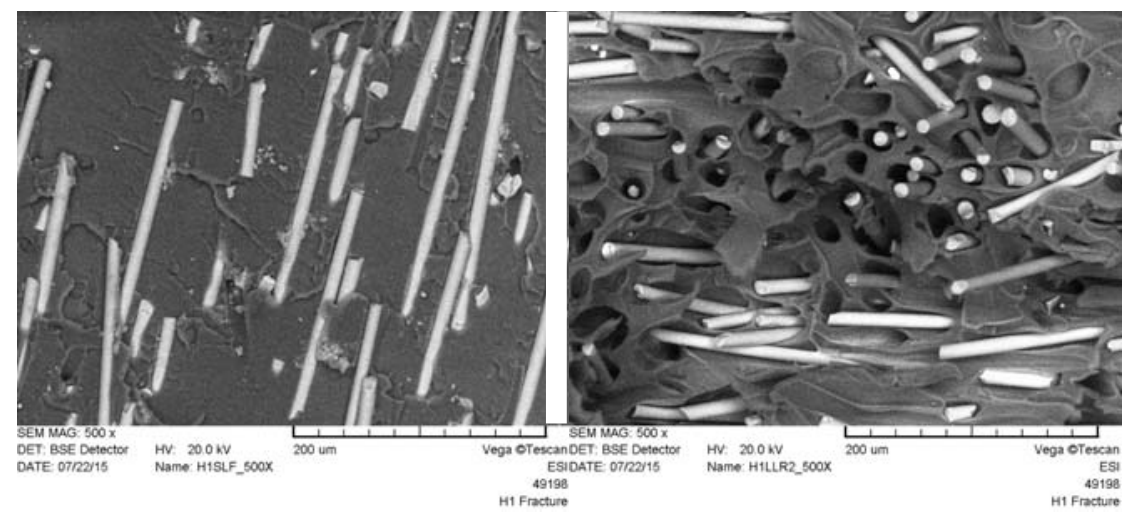

Figure 2. SEM photomicrographs showing the fracture surface morphology in smooth (left) and rough (right) regions of the failed fitting. 